\title{
MAPEAMENTO E CARACTERIZAÇÃO AMBIENTAL NO MUNICÍPIO DE INDEPENDÊNCIA - CEARÁ
}

\author{
Pedro Ítalo Carvalho Aderaldo ${ }^{(a)}$, Frederico de Holanda Bastos. ${ }^{(b)}$ \\ (a) Mestrando em Geografia/Universidade Estadual de Campinas, pedroitaloo@ hotmail.com \\ (b) Prof. Doutor em Geografia/Universidade Estadual do Ceará
}

\section{Eixo: GEOTECNOLOGIAS E MODELAGEM ESPACIAL EM GEOGRAFIA FÍSICA}

\section{Resumo}

\begin{abstract}
O município de Independência apresenta uma significativa variação paisagística, estando presentes depressão sertaneja, maciços residuais, agrupamento de inselbergs e planícies fluviais, possibilitando a análise setorizada de diferentes elementos naturais constituintes das mesmas (FUNCEME, 2009). O estudo considera a análise geossistêmica, amplamente adotada em pesquisas integradas no semiárido brasileiro, que consiste nas relações mútuas entre os componentes do potencial ecológico e da exploração biológica e destes com a ação antrópica. Os procedimentos da pesquisa decorreram de levantamentos bibliográficos, busca por dados cartográficos, ida a campo e visita técnica a órgãos públicos. O trabalho teve como base as contribuições de Souza (2000) que adotou os procedimentos metodológicos para a região Nordeste, focando seu estudo para o semiárido brasileiro. Como principais resultados desta pesquisa, têm-se o mapeamento e a caracterização ambiental em escala municipal, possibilitando subsídios ao planejamento, ordenamento territorial e atividades sustentáveis.
\end{abstract}

Palavras chave: Mapeamento, Caracterização Ambiental, Planejamento Ambiental.

\section{Introdução}

O semiárido do nordeste brasileiro representa $11 \%$ do país. É uma região que abrange o bioma caatinga, o único no mundo. Apresenta-se como uma área rica em biodiversidade e recursos naturais, entretanto mal utilizados, por falta de interesses nacionais e estaduais (ANDRADE, 1970).

Os sertões presentes no contexto nordestino têm marcas evidentes de um passado com práticas predatórias humanas sobre o ambiente natural, degradando as paisagens. As manchas de degradação ambiental se configuram como retrato da difícil relação sociedade - natureza. Se houvesse desde o princípio a preocupação com o manejo adequado dessas práticas, o semiárido nordestino, não apresentaria tantos ambientes de difícil irreversibilidade. Cabe ressaltar que tudo na natureza se configura de forma dinâmica e cíclica.

No contexto das paisagens degradadas no Nordeste, apresenta-se o município de Independência no Estado do Ceará, que possui extensão de 3.218 km², limitando-se ao norte com os municípios de Boa Viagem, Monsenhor Tabosa, Tamboril e Crateús, ao sul com os municípios de Quiteranópolis e Tauá, ao leste com os municípios de Tauá, Pedra Branca e Boa Viagem, a oeste com os municípios de Crateús, Novo Oriente e Quiteronópolis (CEARÁ, 2010). 
OS DESAFIOS DA GEOGRAFIA FÍSICA NA FRONTEIRA DO CONHECIMENTO

Instituto de Geociências - Unicamp

Campinas - SP

28 de Junho à 02 de Julho de 2017

De modo geral, para o melhor entendimento desses ambientes degradados, são de suma importância estudos ambientais, tais como, análises, diagnósticos e relatórios, que busquem um melhor entendimento das dinâmicas presentes, propiciando mudanças sustentáveis, para as atuais e futuras populações. O objetivo do atual trabalho é servir como auxílio no processo de construção desses estudos ambientais, na medida em que se fará uma caracterização ambiental municipal, bem como explanação desse levantamento ambiental em mapas.

Dentre outros motivos da pesquisa, percebe-se que o cenário das relações mútuas e distintas de diferentes paisagens, do município de Independência, encontra-se em níveis consideráveis de degradação, sendo de suma importância, abordar todos os aspectos naturais e individuais das paisagens, que visa contribuir, dentre outros, com o embasamento para as práticas de planejamento ambiental, de ordenamento territorial e de atividades sustentáveis neste município.

\section{Procedimentos Teórico e Metodológico}

Os procedimentos teóricos e metodológicos da pesquisa foram divididos em quatro etapas, tendo o caráter de dependência entre as etapas, para o êxito final. Na primeira etapa, foram feitos levantamentos bibliográficos, objetivando obter informações mais específicas do município de Indepedência, buscando setorizar as informações pertinentes à anàlise geossistêmica. Além da teoria geossistêmica que contempla alguns trabalhos principais como Bertrand (1968) e Sotchava (1978), os conceitos de Tricart (1997) deram suporte a algumas concepções levantadas neste trabalho. No aspecto da caracterização ambiental, Souza (2000) e Ceará (2010), deram um significante suporte. Na segunda etapa foram realizadas as buscas por dados cartográficos, como imagens de satélites, fotografias aéreas, que serviram de base para a construção de um banco de dados georrefenciados, no datum SIRGAS 2000. A realização de todo o trabalho ocorreu sem nenhum custo financeiro adicional, priorizando a utilização de imagens, de dados e de softwares disponibilizados gratuitamente, ou com licença das mais diversas Instituições brasileiras, como o IPECE (Instituto de Pesquisa e Estratégia Econômica do Ceará). Os programas utilizados para a realização do trabalho, foram GvSig 1.11.0 e ArcGIS 9.3. Na terceira etapa foram realizados levantamentos de campo, constatando e comparando a veracidade das informações ambientais obtidas no geoprocessamento. Validando assim toda a parte físico-ambiental dos mapas. Na quarta etapa foram realizados os mapeamentos temáticos, de ordem geológica, geomorfológica, pedológica e fitológica, tendo a hidrologia representada principalmente no mapa geomorfológico. 


\section{Caracterização Ambiental}

O Estado do Ceará é foco de muitos estudos científicos ambientais, voltados principalmente para o semiárido, onde a partir dessas pesquisas foi possível nortear o atual trabalho. Os principais estudos foram os de Souza (2000) e Ceará (2010), sendo possível a partir de suas análises e metodologias configurar toda a caracterização ambiental abaixo.

\section{Geologia}

O estudo geológico para as abordagens das paisagens é primordial, apresentando as bases estruturais que compõem os diferentes relevos e influenciando diretamente e indiretamente em toda a dinâmica natural (Figura 01).

O município de Independência apresenta-se com primazia de terrenos do Pré-Cambriano, sua superfície é parcialmente dissecada em colinas rasas e pediplanadas em rochas do Complexo Nordestino e de suítes magmáticas fortemente deformadas por movimentos distróficos (CEARA, 2010). A leste compreende a área com maior índice altimétrico do município, configurando o maciço de Pedra-Branca ou Troia, que compreende um conjunto de segmentos crustais de provável idade arqueano-paleoproterozoica. Apresenta como unidade litoestratigráfica predominante o Complexo Cruzeta, formado pelas unidades Troia, Pedra Branca e Mombaça. A unidade Troia é constituída por terreno do tipo granito-greenstone belt, formado por rochas metavulcânicas básicas, metagabros, metadacitos e metarriolitos interacamadados com metassedimentos, representados por quartzitos, xistos grafitosos, metacalcários, metachertes e formações ferríferas bandadas. Inclui, ainda, associações com corpos de leucogranitoides e metatonalidos da Suíte Intrusiva Cedro (CPRM, 2007).

A região em questão está localizada na Província Estrutural da Borborema (PB), entre os lineamentos Transbrasilianos e Senador Pompeu. Este domínio é composto por quatro unidades litotectônicas maiores, o núcleo arqueano Tróia-Pedra Branca-Mombaça, embasamento gnaissico paleoproterozóico, rochas supra-crustais neoproterozóicas e complexos granito-migmatítico e granitóides de idade neoproterozóica representados pelo batólito Santa Quitéria, batólito Quixadá-Quixeramobim e núcleo granítico-migmatítico de Maranguape. (CASTRO, 2004).

As unidades presentes no município são bem diversificadas, se apresentando como Unidade Independência, Unidade Tróia, Unidade Canindé, Tauá, dentre outras. Estas são compostas por dioritos, granitóides, granitos, quartzitos, metagrabos, paragnaisses e sequências plutono vulcanosedimentar, que marcam e diversificação a estrutura geológica do município (CPRM, op.cit).

As coberturas aluvionares têm também a sua significância dentro do contexto municipal e até mesmo estadual. Em termos litológicos, estas coberturas de idade quaternária encontradas ao longo dos principais cursos d'água que drenam o município, são compostas por argilas, areias argilosas, 


\section{OS DESAFIOS DA GEOGRAFIA FÍSICA NA FRONTEIRA DO CONHECIMENTO Instituto de Geociências - Unicamp \\ Campinas - SP \\ 28 de Junho à 02 de Julho de 2017}

quartzosas e quartzofeldspáticas, conglomeráticas ou não, além de cascalhos e argilas orgânicas (CPRM, op.cit).

As características dos depósitos aluvionares, em termos de granulometria, extensão e espessura, ficam condicionadas à capacidade de transporte das drenagens, da topografia e da fonte geradora do material transportado. A sedimentologia dos depósitos destes ambientes, consequentemente, reflete um caráter misto de sedimentos fluviais, eólicos e lacustres, onde a presença de depósitos de carapaças de algas diatomáceas é uma característica marcante.

O Estado do Ceará, apesar de não ser tradicionalmente mineiro, apresenta aspectos geoeconômicos interessantes e variados. O município de Independência revela alguns minerais como o ferro, ouro e o rutilo. O ferro e o ouro são encontrados em pequena quantidade, entretanto o rulito tem maior significância. Esse tipo de mineral é proveniente do dióxido de metano, sob a forma de pláceres alúvio-eluviais, apresentando uma camada rutífera com espessura em torno de 1 metro, sob um capeamento estéril de até metro e meio. (CPRM, 2007).

Em relação à classificação das rochas encontradas no município de Independência, estas se configuram como variadas, sendo compostas por rochas ígneas e metamórficas, principalmente nos maciços residuais registrados à leste e sudeste, na depressão sertaneja e nos inselbergs. As estruturas sedimentares se resumem aos pontos setorizados na paisagem municipal, se restringindo a parte sudoeste e sendo formada principalmente por depósitos aluviais.

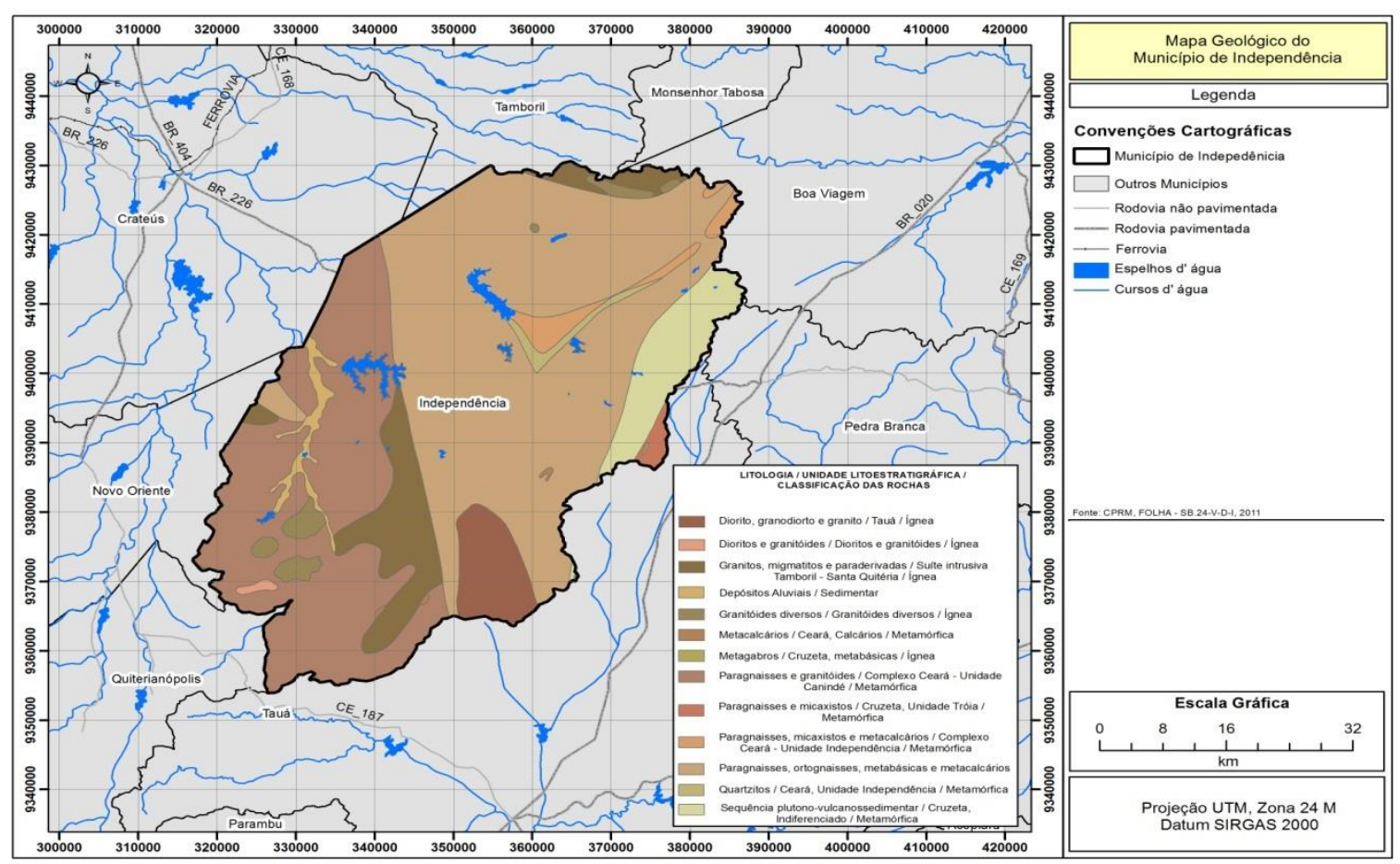

Figura 01: Mapa Geológico do Município de Independência. Fonte: CPRM. Folha-SB.24-V-D-1, 2011. 


\section{Geomorfologia}

A morfologia do município é bem característica das áreas susceptíveis à desertificação, com predomínio de topografias planas ou levemente onduladas e com altimetrias abaixo de 400m (Figura 02). Apresentando maciços residuais na borda leste do município, como o maciço de Pedra Branca, com altitude de $800 \mathrm{~m}$ em média e a sudeste do município a serra da Joaninha com média altimétrica de 500m (CEARÁ, 2010).

A morfologia da depressão sertaneja se expõe através dos pedimentos que se inclinam desde a base dos maciços residuais e dos inselbergs, configurando a maior unidade geomorfológica de Independência. $\mathrm{O}$ gradiente topográfico do município tem decaimento suave no sentido dos vales e do litoral, bem como todo o Estado do Ceará (SOUZA, 2000). A depressão sertaneja retratada no município de Independência expõe-se como uma área altamente degradada, apresentando solos exposto, rasos e com baixa fertilidade, irregularidade pluviométrica, sobrepastoreio, processos erosivos, apresentando ravinamento, dentre outros, que estão associados diretamente com o antropismo, na medida em que a sociedade degrada sem levar em consideração a capacidade de suporte do ambiente.

Os maciços residuais presentes também apresentam níveis de degradação ambiental consideráveis. Sua morfologia se caracteriza como dissecadas em colinas rasas e em cristas desenvolvidas por rochas do embasamento cristalino, apresentando vales em "V". Existem também nos maciços residuais as planícies alveolares que se formaram através dos processos deposicionais, com deposição coluviais e aluviais, possibilitando diferentes tipos de solos (SOUZA. 2000). Os vales em forma de "V" mostram um maior potencial da drenagem, entalhando a rocha e formando esses vales dissecados.

Os inselbergs que são relevos isolados em superfícies de aplainamento, resulta da erosão diferencial, morfologicamente apresentam vertentes de fortes declives e feições de topos aguçados com rochas do tipo granitóides e quartzitos.

As planícies fluviais bem como as planícies lacustres, exibem-se em todo o município como paisagens de exceção, por estarem presentes, os melhores tipos de solos e de fontes hídricas, propiciando o grande uso e ocupação. Como exemplo histórico está o surgimento de distritos e cidades bem próximos às margens fluviais. Em Independência essa dinâmica não se difere, sendo margeada pelo rio Independência, dando condições ambientais diferentes das encontradas nos sertões em volta. 

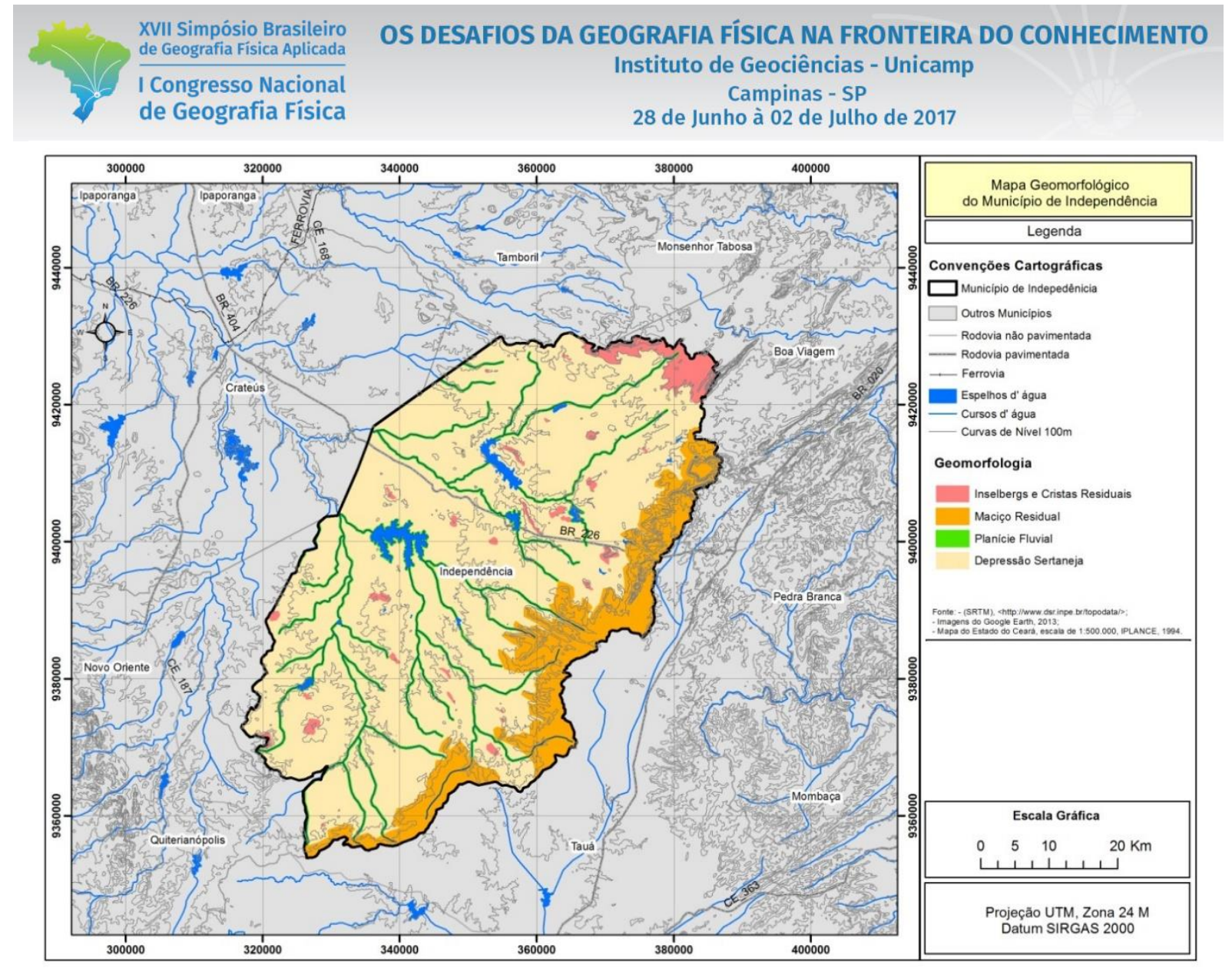

Figura 02: Mapa Geomorfológico do Município de Independência. Fonte: Topodata/INPE; Imagens do Google Earth, 2013; Mapa do Estado do Ceará, IPECE.

\section{Clima}

A importância do clima no contexto do meio físico se dá sob as mais diferentes formas, mas, principalmente em relação ao tipo de intemperismo predominante, às morfologias derivadas em boa parte desse predomínio e da intensidade intempérica, à participação na formação dos solos, no condicionamento direto e indireto dos recursos hídricos, sem falar no desenvolvimento dos diversos tipos de cobertura vegetal.

As características climáticas do Ceará têm origem em, basicamente, três sistemas sinóticos geradores de precipitação que regem a circulação atmosférica, são elas: a Zona de Convergência Intertropical (ZCIT), as frentes frias, com sua formação original no pólo Sul e que oscila dentro da faixa de trópicos e um Centro de Vorticidade Ciclônica, com tempo de atuação variável dentro do período de chuvas.

A ZCIT é um dos fatores mais importante na determinação da intensidade das chuvas, sobretudo, na parte setentrional do Nordeste brasileiro. Este sistema (ZCIT) apresenta um deslocamento Norte-Sul durante o verão boreal, em direção a posições mais ao Sul, durante o verão austral, ou seja, o sistema atinge sua posição máxima no Hemisfério Sul em torno do equinócio outonal (23 de março), retornando ao Hemisfério Norte, quando o período chuvoso entra em declínio. (CEARÁ, 2010). 


\section{OS DESAFIOS DA GEOGRAFIA FÍSICA NA FRONTEIRA DO CONHECIMENTO Instituto de Geociências - Unicamp$$
\text { Campinas - SP }
$$ \\ 28 de Junho à 02 de Julho de 2017}

$\mathrm{Na}$ região em estudo, a Zona de Convergência Intertropical (ZCIT) representa o principal sistema sinóptico responsável pelas condições climáticas, em particular pelo estabelecimento da estação chuvosa.

No Estado do Ceará, o município de Independência insere-se no domínio morfoclimático das caatingas semiáridas, constituindo-se no chamado polígono das secas do Nordeste. Desta forma, o ambiente é marcado pelas irregularidades pluviométricas provocadas pelos efeitos da semiaridez, que traduzem-se nas deficiências hídricas pronunciadas que ocorrem durante maior parte do ano.

O município de Independência está condicionado pelo clima semiárido, com índices pluviométricos entre 500 e $800 \mathrm{~mm}$, concentrando suas chuvas no período de três a quatro meses, existindo grande irregularidade tempo e espacial. Suas altas taxas de evaporação e evapotranspiração, propiciada pela quantidade de raios solares, influenciam diretamente no balanço hídrico municipal, dificultando o armazenamento hídrico nos reservatórios e consequentemente interferindo na dinâmica social do município (CEARÁ, 2010).

\section{Pedologia}

As denominações dos tipos de solos utilizadas neste trabalho estão de acordo com o atual sistema brasileiro de classificação de solos da Empresa Brasileira de Pesquisa Agropecuária - EMBRAPA, de 2013. No município o que se leva mais em consideração para a atual conjuntura pedológica, são a presença de relevo aplainado, rochas cristalinas e clima semiárido (Figura 03). O clima semiárido tanto em escala municipal como estadual, apresenta-se interferindo na pedologia predominante. $\mathrm{O}$ município por estar nas baixas latitudes apresenta grande fluxo de energia, ativando constantemente processos de evaporação, evapotranspiração e salinização, que são característicos de clima semiárido.

O município de Independência apresenta em alguns trechos solos degradados, com grande presença de rocha exposta, consideráveis níveis de salinidade e com difícil recuperação para utilização. As atividades impostas pelo homem e suas atividades econômicas sob esse tipo de componente ambiental, gerou agravamentos para a sobrevivência no campo e na cidade, na medida em que o sertanejo ao longo do tempo tem como subsídios para a sua sobrevivência as práticas agrícolas e pecuária. Os solos presentes no município se resumem a Planossolo Solódico, Luvissolos, Neossolos Litólicos e Argissolos Vermelho-Amarelo. 

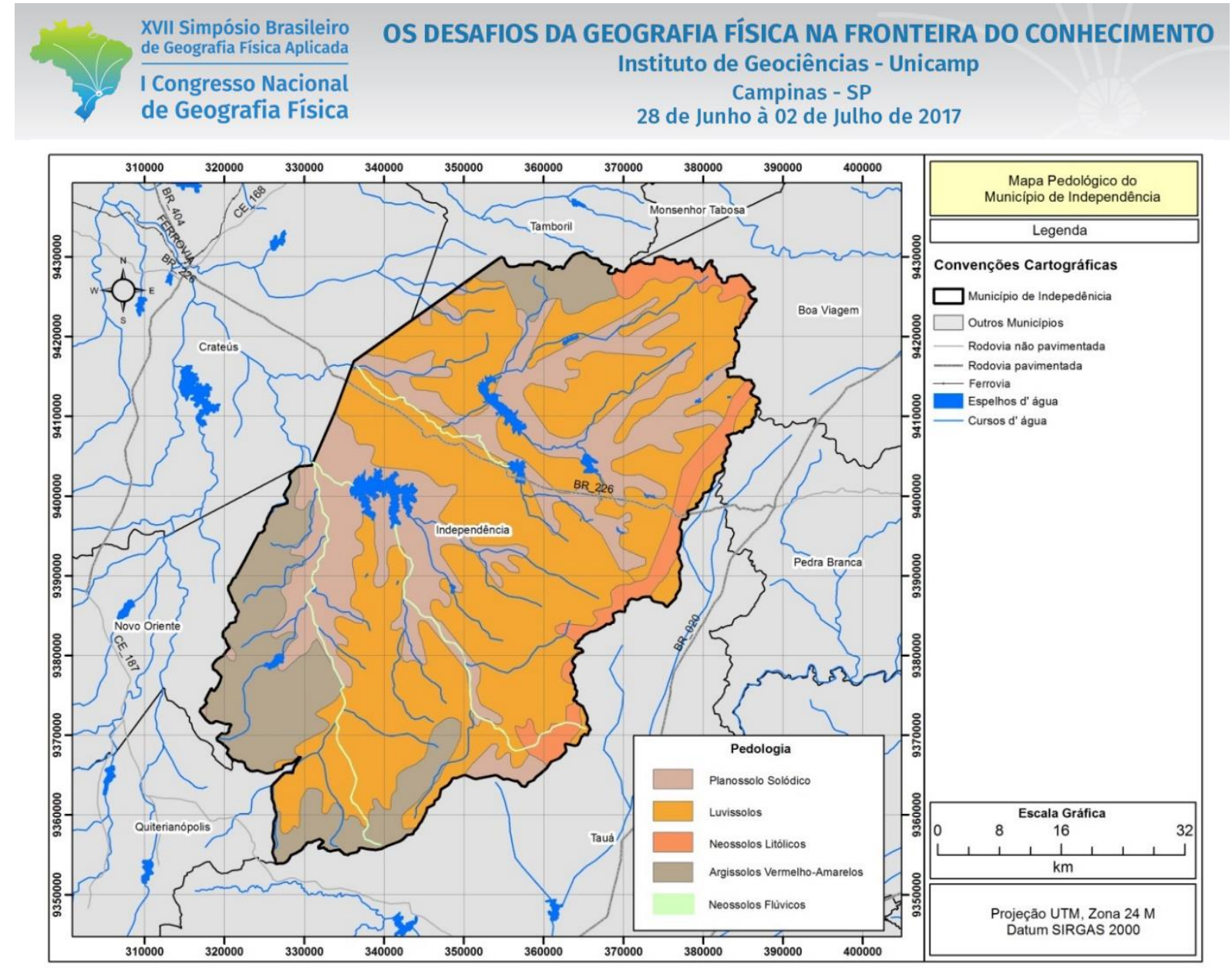

Figura 03: Mapa Pedológico do Município de Independência. Fonte: http://www.dpi.inpe.br/Ambdata/mapa_solos.php

\section{Hidrologia}

O município encontra-se dentro da Bacia do Rio Parnaíba, a única bacia hidrográfica do Estado do Ceará que deságua em outro Estado. Todos os rios do município são intermitentes, secam na estação seca, existindo apenas três rios perenes, como o Independência, o Curiú e o Santa Cruz, que são formados pela vazante dos açudes Cupim, Jaburu II e Barra Velha (Figura 04), respectivamente. O regime hidrológico dos reservatórios é condicionado principalmente dentre outros fatores, pela má regularidade das chuvas e pelas condições geológicas da área. Nos períodos chuvosos, o escoamento ao longo dos rios presentes no município, são bastante consideráveis, entretanto, dentro de um período curto, após o fim das precipitações, verifica-se ainda o escoamento das suas lâminas d'água, entretanto com menores fluxos, proporcionado por os rios estarem sobre cristalino e consequentemente em razão de sua baixa porosidade e baixa taxa de infiltração. Nesse sentido as condições físicas caracterizadas pela presença do embasamento cristalino, datadas do pré-cambriano implicam a ocorrência de padrões de drenagem dendríticas e subdendriticas gerando uma elevada taxa de escoamento no sentido jusante. 
XVII Simpósio Brasileiro

de Geografia Fisica Aplicada

I Congresso Nacional

de Geografia Física

\section{OS DESAFIOS DA GEOGRAFIA FÍSICA NA FRONTEIRA DO CONHECIMENTO \\ Instituto de Geociências - Unicamp \\ Campinas - SP \\ 28 de Junho à 02 de Julho de 2017}

$\mathrm{O}$ retrato da conjuntura hidrológica do município é condicionada principalmente pelos fatores climáticos e antrópicos, na medida em que se configura como uma área semiárida e com grande presença de atividades predatórias que interferem diretamente na dinâmica hídrica municipal. Necessitando da construção de açudes para minimizar os problemas com o déficit hídrico tanto para

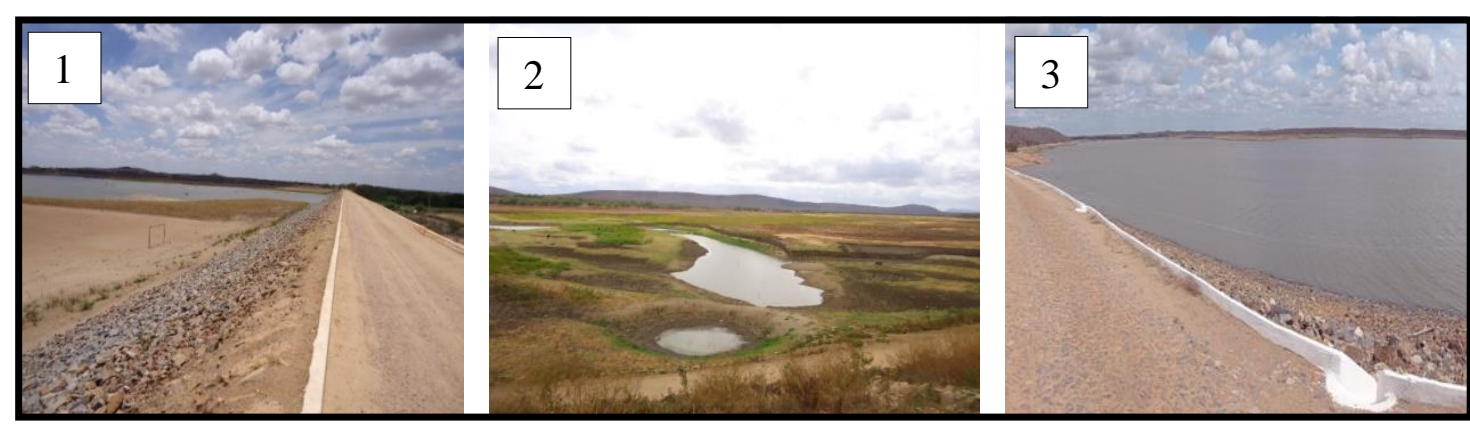

o próprio ambiente, como para a população.

Figura 04: Foto 1-Açude Jaburu II; Foto 2-Cupim; Foto 3-Açude Barra Velha. Fotos no período seco. Fonte: Pedro Aderaldo. Ano: 2013.

\section{Vegetação}

A vegetação é o reflexo de toda a dinâmica dos elementos naturais, na medida em que se comporta como o ser vivo respondendo aos estímulos das modificações e alterações ocasionadas na paisagem (Figura 05).

A vegetação local pertence ao bioma caatinga, palavra indígena que significa "mata aberta, clara", em contraposição às matas fechadas, escuras. De acordo com a classificação da vegetação, a caatinga é um complexo vegetacional constituído por arvoretas e arbustos decíduos durante a seca, com presença frequente de espinhos, perdendo suas folhas no período seco e apresentando um verde exuberante no período chuvoso. São comuns: herbáceas, quase todas anuais, cactáceas e bromeliáceas. Apresenta ainda muitos râmulos secos e duros, mais ou menos espiniformes. As folhas das árvores e arbustos, em geral, são pequenas e compostas. São espécies com longa história de adaptação ao calor e à baixa umidade do domínio semiárido regional. Apesar da condição de semiaridez, a caatinga abriga uma grande diversidade de espécies tanto da fauna como da flora, sendo grande parte endêmica do Nordeste Brasileiro.

No município de Independência, a vegetação predominante é apresentada de três formas (Figura 06). A caatinga arbustiva aberta, tendo a maior ocorrência na região, composta de árvores e arbustos de alturas variáveis esparsamente distribuídas, presença de plantas suculentas (cactáceas) sobre um estrato herbáceo estacional. A caatinga arbustiva pode ser distinguida de vários modos, entre eles, quanto ao porte das plantas lenhosas. A caatinga arbórea, apresentando dominância de um estrato lenhoso, denso de árvores e arvoretas, em média de 7,0 a 10,0 $\mathrm{m}$ de altura, a caatinga arbórea também 


\section{OS DESAFIOS DA GEOGRAFIA FÍSICA NA FRONTEIRA DO CONHECIMENTO Instituto de Geociências - Unicamp Campinas - SP \\ 28 de Junho à 02 de Julho de 2017}

é composta por um estrato intermediário de arbustos espinhosos. Por último a agricultura, na medida em que este tipo de vegetação também se diferencia nos ambientes rurais e urbanos dentro de uma mesma região. Temos nas zonas rurais predominância de espécies frutíferas, leguminosas e outras que fornecem algum tipo de alimento onde as famílias mantêm sua subsistência. Já nas áreas urbanizadas a predominância é de plantas ornamentais (Andrade-Lima, 1891).

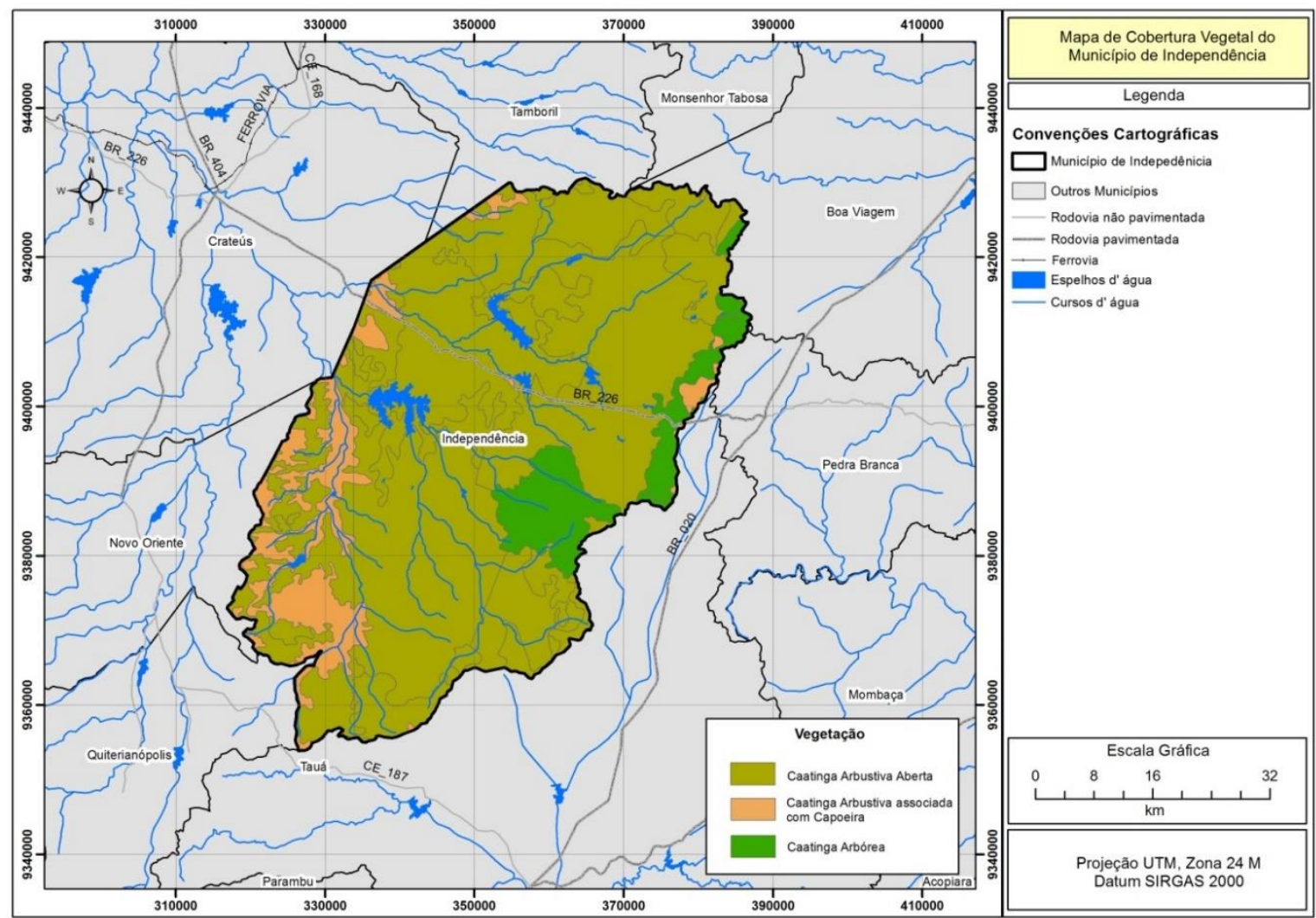

Figura 05: Mapa Fitológico do Município de Independência. Fonte:

http://www.dpi.inpe.br/Ambdata/mapa_sipam.php; CEARÁ, 2010.

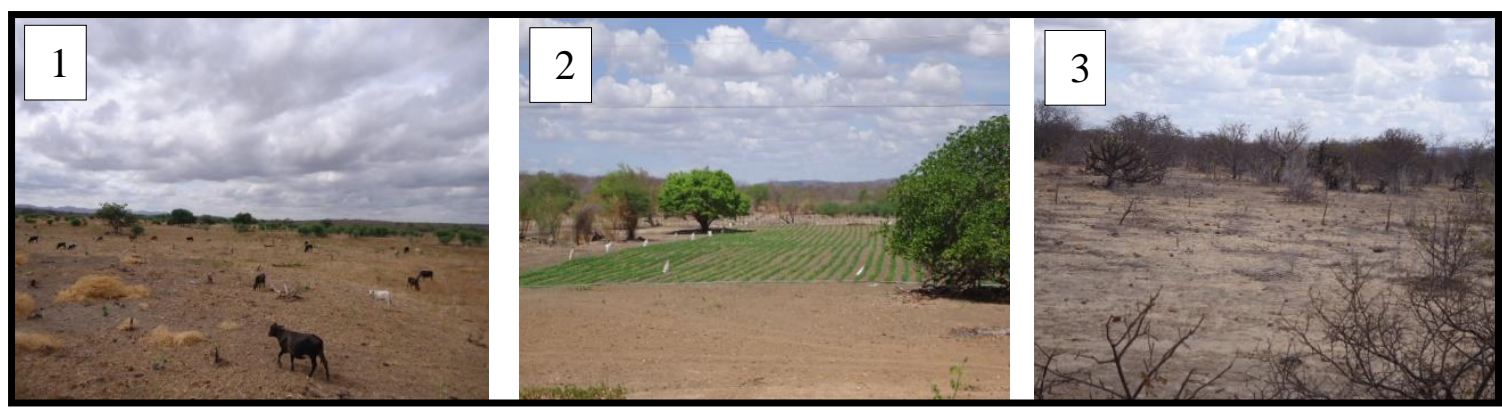

Figura 06: Foto 1-Pastagem; Foto 2-Agricultura; Foto 3-Capoeira com Caatinga Arbustiva ao Fundo. Fotos no Período Seco. Fonte: Pedro Aderaldo. Ano: 2013. 


\section{Conclusão}

O município de Independência ainda é pouco estudado, principalmente no quesito ambiental. A maioria dos estudos que contemplam o município está em escala estadual ou até mesmo regional, motivando ainda mais a realização desse trabalho, que foi apresentado totalmente em escala municipal. Após a conclusão da pesquisa, o presente trabalho busca sintetizar os principais resultados e os aspectos mais importantes da discussão em torno da caracterização ambiental do município de Independência. Apresentando os elementos formadores de paisagens, como os geológicos, os geomorfológicos, os hidrológicos, os climatológicos, os pedológicos e os fitológicos.

Ao passo que o município encontra-se em níveis de degradações elevados, encontrando-se em áreas desertificadas, o atual estudo se torna de grande importância, por buscar caracterizar os elementos naturais da paisagem e especializar os dados em mapas, subsidiando dentre outros, atividades de planejamento ambiental e diagnósticos ambientais.

\section{Bibliografia}

ANDRADE, M. C. de. Nordeste, espaço e tempo. Petrópolis: Vozes, 1970.

ANDRADE-LIMA, D. The caatinga dominium. Revista Brasileira de Botânica. 1981

BERTALANFFY, L. V.Teoria geral dos sistemas. Petrópolis: Vozes, 1973.

BERTRAND, G. Paysage et géographie physique globale: esquisse méthodologique. Revue géographique des Pyrénées et sud-ouest v. 39, fasc. 3, p. 249-272, 3 fig., 2 pol. Phot.h.t. 1968.

CASTRO, N. A. Evolução Geológica Proterozóica da Região entre Madalena e Taperuaba Domínio Tectônico Ceará Central (Província Borborema). 2004. 221p. Tese (Programa de Pós-Graduação em Geoquímica e Geotectônica) - Instituto de Geociências,Universidade de São Paulo, São Paulo. 2004.

CEARÁ. Programa de Ação Estadual de Combate à Desertificação e Mitigação dos Efeitos da Seca, PAECE. Fortaleza: Ministério do Meio Ambiente / Secretaria dos Recursos Hídricos, 2010.

CPRM - Serviço Geológico do Brasil Implantação de sistema simplificado de abastecimento de água na Comunidade Fazenda Croatá, Município de Independência - CE. Relatório sintetizado / organizado: Antonio Artur Cortez ...[et al.]. - Recife: CPRM/MIN, 2007. 
FUNCEME. Compartimentação geoambiental do Estado do Ceará. Fundação Cearense de Metereologia e Recursos Hídricos - Fortaleza, 2009.

IBGE. Mapas Físicos. Disponível em: http://mapas.ibge.gov.br/fisicos. Acessado em:19/11/2013.

INPE. Mapa de solos. Ambdata. Disponível em: http://www.dpi.inpe.br/Ambdata/mapa_solos.php. Acessado em: 03/04/2017.

INPE. Mapa de vegetação. Ambdata. Disponível em: http://www.dpi.inpe.br/Ambdata/mapa_sipam.php Acessado em: 03/04/2017

IPECE. Base Cartográfica. 2008. Nota técnica n ${ }^{\text {3 } 35 . ~ D i s p o n i ́ v e l ~ n a ~ i n t e r n e t: ~ w w w . i p e c e . c e . g o v . b r . ~ A c e s s o ~ e m: ~}$ $01 / 12 / 2013$

SEMACE. Mapa de Unidades Geoambientais do Estado do Ceará. Diagnóstico e Macrozoneamento do Estado do Ceará. FCPC/SEMACE, 1998.

SOTCHAVA, V.B. Por uma teoria de classificação de geossistemas de vida terrestre.Biogeografia, 13. São Paulo: Instituto de Geografia da Universidade de São Paulo, 1978.

SOUZA, M. J. N. Bases naturais e esboço do zonemento geoambiental do Estado do Ceará.Fortaleza: 2000. Ed. FUNECE.

TRICART, J. Ecodinâmica. Rio de Janeiro, IBGE, Diretoria Técnica, SUPREN, 1997, Curitiba. 